designed by $M$. Nogues, of the Marey Institute of Paris, by means of which it is possible to take up to 300 photographs per second of moving objects. This is perhaps the best method of analysis of reflex movements and muscular adjustments, such as those of posture. In presentation such movements can be made to occupy ten to fifteen times their normal time. Heavy electric leads are carried to this room so that brilliant illumination by arc or mercury lamps may be employed; while the flat roof is admirably adapted to the purpose of cinematography in summer.

The X-ray department is equipped with the latest type of apparatus for radiography in all its medical branches. Facilities are provided for rapid work as well as for the study of movement and anatomical structure as revealed by the latest X-ray technique of the day. The power unit consists of a ro $\mathrm{kw}$. transformer X-ray set, which supplies energy to the $\mathrm{X}$-ray tubes either when working from below or above the operating tables, or when used for fluoroscopy; and arrangements are made whereby the portable trolley control may be connected either at a position near the tables or at a separate wall plug adjacent to the fluorescent screening-stand at the far end of the room.

One of the X-ray operating tables is fitted with automatically moving plate carriers beneath the top, which itself is hinged so as to render the tube box and diaphragm mechanisms readily accessible. The other operating table is fitted with a Potter-Bucky grid, and is the second table of the kind that has come to this country from the United States. As well as a large screening apparatus, there is a heavy type tube stand for general use, and a number of minor accessories. Apparatus for the special radiography of the head is also provided.

The high-tension overhead leads are made of nickelplated tubing of sufficient diameter to reduce the formation of corona to a minimum, and a hightension switch actuated by strings serves to connect the transformer terminals with the set of leads required for each apparatus as desired. The protection of all engaged in the work of the department has been carefully provided for, and stray radiation prevented from entering adjacent rooms by a covering of lead six feet high upon the walls. The lead sheet carefully lapped at the joints is hidden beneath stout boarding which serves to absorb the soft component of any secondary radiation which may be produced from the lead by stray radiation. The floor is covered with rubber. An adjoining dark room and large viewing room, together with a plate store, completes the department.

The installation has been carried out by Messrs. Watson and Sons (Electro-Medical), Ltd., London, who not only did the work of equipping the X-ray rooms, but also gave Major Phillips the benefit of their experience in designing $\mathrm{X}$-ray apparatus.

The Rockefeller Gift has also rendered it possible to effect certain much-needed alterations and extensions in the departments of bio-chemistry, pharmacology, and physiology. On the ground floor the general bio-chemical laboratory receives an extension behind the anatomy theatre, providing additional places for advanced students in bio-chemistry. The bio-chemical research laboratories are also enlarged by taking in the whole ground floor of the pharmacology building, providing in this way two additional research laboratories and a private room for the professor of bio-chemistry. In pharmacology further accommodation for research is provided by dividing the present pharmacology lecture theatre into two. laboratories. The pharmacology lectures will be delivered in future in the physiology theatre. This department receives also two extra laboratories on the second floor of the physiology building in compensation for the ground-floor laboratories surrendered to bio-chemistry.

A large part of the first, second, and third floors of the building connecting the present Institute of Physiology with the Institute of Anatomy is used for increasing the laboratory accommodation for research in physiology.

Concerning the architecture, the Gower Street front is entirely in Portland stone; the back portions in Arlesey brick with stone dressings to match the existing physiology and pharmacology buildings. The floor of the dissecting room, annexe, and prosectorium is of white mosaic, and the walls of white glazed brick. On the corridors is a strip three feet wide of quarter-inch cork carpet, with margins of white terrazzo in the basement, and of oak or pitch pine on other floors. A dado of terrazzo with green panels and white frames runs up the whole of the staircase and along the sides of the principal corridors. The floors of most of the working-rooms are cement, covered with linoleum. The steps and landing of the staircase are oak on concrete, with iron balustrade; and the museum, library, periodical room, and entrance vestibule from Gower Street have oak floors.

A passenger lift runs from the basement to the top of the building, serving all floors, and hand-power lifts are provided from the injection room down to the tank room, and from the tank room up to the annexe of the dissecting room. The whole of the building is steel frame construction.

It is of interest that the house in which Charles Darwin began the compilation of the notebooks for his "Origin of Species " is only four doors away from the new building, and it is hoped that eventually upon this site will be built a Darwin Institute of Anthropology and Biology which will worthily commemorate the greatest of English biologists.

\title{
Applications of Physics to the Ceramic Industries.
}

THE ceramic industries formed the subject of the fourth of the series of lectures on "Physics in Industry " which are being given under the auspices of the Institute of Physics, and the lecture was given by Dr. J. W. Mellor on May 9 at the Institution of Electrical Engineers. Sir J. J. Thomson, president of the Institute, was in the chair. Eliminating such applications of physics as are common to other industries, Dr. Mellor dwelt only on specific applications of sound, light, heat, electricity and magnetism, and mechanical science in the manufacture of pottery and glassware. He made it clear that, while in these industries much has been done to utilise physical principles and knowledge, there remains a very wide field in which present practice is crude and unscientific, and where all the help which the physicist can give is needed to replace obsolete, rule-of-thumb procedure by methods which are exact, efficient, and trustworthy.

Up-to-date manufacturers are following with keen interest the various attempts now being made to produce a mode of illumination to imitate natural light, for the matching of coloured glazes under artificial light is usually difficult and sometimes impossible. In one example quoted where the coloux of a nickel-blue tile had to be imitated, it appeared that the copy was green in gas-light and blue in daylight. Many chrome colours which appear green in 
daylight are crimson, pink, or purple in gas or electric light. During the War, blue lamp bulbs were needed, but they had to appear blue when illuminated by the glow of a red filament. Had absorption spectra of colouring oxides been available, much money and labour spent in fruitless experiments would have been saved.

It was due to the measurements made by physicists on the indices of refraction of small crystals that the two crystalline forms of silica were detected, and the knowledge of the transformations has placed the whole manufacture of silica bricks on a sound scientific foundation. Recent work on X-ray spectra promises shortly to do. for the fire-brick manufacturer what a knowledge of indices of refraction has done for the silica-brick manufacture.

Applications of magnetism have been but partially explored. One problem that has been almost solved is the separation of particles of metallic iron from clay slip. A system of electromagnets made by the Rapid Magnetting Company is ingeniously arranged so that if the magnets cease to work, the dirty slip will not pass into the purified slip. Success, however, has not yet been attained in removing particles of cupriferous pyrites from fire-clays.

The physicist-engineer specialising in heat problems has an illimitable field for his knowledge and skill. Dr. Mellor estimates that in firing biscuit-ware only 2 per cent. of the fuel is usefully employed, although the processes of brick-firing are much more efficient. Another series of problems awaiting solution is connected with the drying of clays and clay-ware, where serious losses occur owing to the development of drying cracks unless an inordinately long time is allowed. It appears that little progress is possible until the physicist has worked out the distribution of water in the interior of a drying mass of clay, and he will obviously have to take into account the relation between the surface of the drying solid and the humidity of the surrounding atmosphere.

Dr. Mellor referred to the studies of the thermal strains in "ideal" kilns upon which Prof. Lees is engaged; later it is hoped to apply these results to actual kilns, and he expressed the wish that Prof. Lees would pass on to consider contraction strains set up during the uneven drying and firing of special shapes. The results of such an investigation will not only explain why some shapes fracture and others do not, but they will also indicate to the designer of chemical and sanitary apparatus, furnaces and coke ovens, the shapes to be avoided on account of the narrow margin of safety in manufacture and use. Numerous interesting problems relating to the grain of clay await solution. It appears, for example, that the particles can be oriented differently so that the drying and firing contractions are different in different directions. Then there is the plasticity of clays to be studied, and, indeed, the whole problem of the hydrostatics and dynamics of liquids with an indefinitely large number of particles in suspension. Akin to this are the colloidal problems-now ever with us-but for some unaccountable reason, which he ascribed to chance, Dr. Mellor preferred to label this branch of his subject as chemistry and not physics.

Electricity is usefully employed in high temperature testing work, and also for crucible furnaces, but a satisfactory electric furnace for firing pottery has not yet been evolved, and in any case the cost of power is here a paramount consideration. Dr. Mellor indicated the novel problems connected with the effects of convection currents of hot air that would have to be solved if electrically-heated furnaces or kilns came into use. The conditions are quite different from those in gas- or coal-fired furnaces.
In conclusion Dr. Mellor referred to the physical problems connected with the glazing of pottery. The governing condition here is that the thermal expansion of glaze and body should be the same. Data so far obtained have not taken sufficiently into consideration the complex adjustment of glaze and body; for example, there is the tensile strength of the glaze to be considered, as well as the rate at which the glaze attacks the body and the effect of solution of the body in the glaze and its coefficient of expansion.

The lecturer's statement of the case for much closer co-operation between the ceramist and the physicist than has hitherto obtained was forcible and convincing.

\section{The Meteorology of Scott's Last Journey.}

THE Halley lecture for 1923 was delivered at Oxford on May I7 by Dr. G. C. Simpson, the director of the Meteorological Office, who took for the subject of his lecture "The Meteorology of Scott's Last March."

The polar party left Hut Point on November 3 , I 9 II, and first traversed the Barrier, where it experienced a remarkable daily variation of temperature. In spite of the fact that the sun was continually above the horizon, varying only from $10^{\circ}$ above the southern horizon at midnight to about $30^{\circ}$ above the northern horizon at mid-day, the regular daily temperature variation on cloudless days reached the enormous value of $20^{\circ} \mathrm{F}$. This necessitated travelling by night and resting by day. Several serious blizzards were encountered.

It is now clear that the Barrier blizzard is extremely local, being confined to the western half of the Barrier. During ten months with simultaneous observation at Framheim-Amundsen's winter quarters in the east-and at Cape Evans in the west, winds of more than thirty miles an hour occurred during 30 per cent. of the time at Cape Evans, and only 2 per cent. at Framheim. This is due to the fact that when the pressure is higher over the Barrier than over the Ross Sea the air tends to flow from the Barrier northwards to the sea, but is deflected to the west by the earth's rotation. The edge of the western plateau extends like a wall 8000 feet high for more than a thousand miles along the west of the Barrier and of the Ross Sea. This prevents the air moving freely to the west, with the consequence that the air-flow from the whole of the Barrier is concentrated in the west, and moves northward with high velocity, giving rise to the familiar blizzard.

When the polar party was at the foot of the Beardmore Glacier it experienced a serious blizzard which gave the greatest snowfall ever recorded in high southern latitudes. The cause of this bad weather was the formation of a deep depression over the Ross Sea, which produced a great flow of warm air from the Ross Sea to the south of the Barrier.

On reaching the plateau, low temperatures were experienced. During the five weeks that Scott and his party were on the plateau the mean temperature was $-19^{\circ} \mathrm{F}$., with a maximum of $-3^{\circ} \mathrm{F}$., and a minimum of $-30^{\circ} \mathrm{F}$. As they descended from the plateau, the temperature at first rose in the normal way, but while the party was still on the glacier a great change in the weather occurred. From this date-February I I-until March 20, extremely abnormal conditions were experienced. There was little or no wind, the temperature fell rapidly to the neighbourhood of $-40^{\circ} \mathrm{F}$., and ice crystals were deposited from the cold air upon the surface which acted like sand on the runners of the sledge. These thirty-nine days were the deciding factor in the fate

No. 2796 , VOL. $x 11]$ 